\title{
INTERTEXTUALIDAD, HERMENÉUTICA Y LITUR GIA EN LOS AUTOS DE CALDERÓN. A PROPÓSITO DE TRIUNFAR MURIENDO
}

\author{
Víctor García Ruiz \\ Universidad de Navarra \\ [Anuario calderoniano (ISSN: 1888-8046), 2, 2009, pp. 181-205]
}

Uno de los recientes éxitos de ventas a escala mundial ha sido el libro de Benedicto XVI titulado Jesús de Nazaret. En ese libro el actual Papa recoge algunas de sus viejas preocupaciones en torno a la interpretación del texto bíblico en relación con la teología. De manera especial hace hincapié tanto en la necesidad como en las limitaciones del método-histórico crítico aplicado a la Escritura. Es una necesidad que deja clara Nietzsche, el filólogo, en un sarcástico pasaje de El anticristo:

[Un] distintivo del teólogo es su incapacidad para la filología. Por filología debe entenderse aquí, en un sentido muy general, el arte de leer bien: el poder leer hechos $\sin$ falsearlos con interpretaciones, sin perder, por afán de comprender, la precaución, la paciencia, la sutileza. Filología como ephexis [indecisión] en la interpretación: trátese de libros, de novedades periodísticas, de destinos o de hechos meteorológicos — para no hablar de la «salvación del alma»... El modo como un teólogo, lo mismo 
en Berlín que en Roma, interpreta una «palabra de la Escritura» o un acontecimiento, una victoria del ejército de su patria, por ejemplo, a la luz superior de los salmos de David, es siempre tan audaz que un filólogo, al ver eso, se sube por las paredes. (p. 100)

Ignoro si Nietzsche leyó algún auto sacramental calderoniano pero, en tal caso, no tengo la menor duda de que, en efecto, se subió por las paredes. Los autos calderonianos reflejan una interpretación profundamente simbólica de la Escritura porque se alimentan, casi en exclusiva, de la alegoresis elaborada por la Patrística cristiana de los primeros siglos. Como es bien sabido, la interpretación alegórica de la Biblia es uno de los grandes hallazgos desarrollados por los Padres de la primitiva teología cristiana en su proceso de desgajamiento de las comunidades judías. En ese desgajamiento, el problema fundamental era la posición de la Biblia Hebrea, la Ley, los Profetas y los Escritos ${ }^{1}$, eso que los cristianos terminaron denominando Antiguo Testamento, en oposición a los nuevos relatos evangélicos centrados en Jesús. Tanto los judíos como las primeras comunidades judeo-cristianas buscaban interpretar la Escritura, en especial la Torá. Pero para los judíos interpretar la Torá (la Ley, contenida en el Pentateuco) significaba descubrir un significado secreto, escondido, no evidente, en la palabra revelada por Yahvé, norma única de vida para el pueblo.

En cambio, para los cristianos, interpretar la Escritura consistía, cada vez más, en considerarla el Antiguo Testamento; es decir, no querían descubrir en ella una norma que Yahvé imparte de forma más o menos oculta. Lo que les guía en su lectura de la Biblia es la noción de cumplimiento de una acción anunciada previamente por Dios. O si se quiere, las comunidades cristianas también quieren descubrir algo en

1 Torá, Nebiim y Ketubim, llamados en conjunto «Tanak». El judaísmo distingue tres niveles de inspiración en el Antiguo Testamento. La Torá es directa y rigurosamente "palabra de Dios", incluso en el orden de las palabras; de ahí métodos exegéticos como la guematria (asignar valores numéricos a las palabras) o el notarikon (leer las palabras como siglas) y otros, ya francamente esotéricos, como el atbash (hacer dos columas con las letras del alefato, una empezando por alef y otra por tau; sustituir las letras de una frase por las correspondientes letras de la columna inversa; si la frase tiene sentido, eso es también palabra de Dios). Los Profetas no es palabra de Yahvé sino una valoración, autorizada pero no divina, de la historia judía a la luz de la Torá. Los Escritos (salmos y sapienciales) son palabra humana de los sabios que hablan de Dios y del hombre. 
la Escritura, pero no normas de conducta sino anuncios. ¿Anuncios de qué? Anuncios de lo que ya saben que llegó: Cristo, el acontecimiento fundamental. La vida de Jesús engendra una tradición que lleva a algunos extremistas a querer prescindir de la Biblia Hebrea en favor de esa nueva tradición engendrada por la vida de Jesús, que está siendo recogida por escrito ya en el primer siglo. La solución de la comunidad cristiana a la cuestión de cómo entender la Biblia Hebrea fue interpretarla como relativa a Cristo y a su palabra definitiva. Es decir, entender el Antiguo Testamento como un Primer Testamento, válido pero limitado.

El instrumento hermenéutico que hizo posible esta exegesis de plenitud escatológica fue la alegoresis. La alegoresis - desarrollada por Filón de Alejandría o el Judío, Clemente de Alejandría, los alejandrinos y, a gran escala, por Orígenes- consistía en una interpretación conceptual del texto veterotestamentario, entendido como metáfora de Cristo. Una exegesis «retrospectiva» y simbólica o "poética». El fundamento científico era de origen platónico y debía relacionar el texto bíblico con un concepto más amplio que, por su sentido, desembocara de manera natural en la Idea última a que alude verdaderamente o que contiene de forma germinal. Como, para los Padres, la Idea última está clara - es Cristo- lo único que queda es mostrar de qué manera concreta los hechos y palabras del Antiguo Testamento son, en realidad, símbolos de Cristo. La alegoresis, por tanto, tiene un componente fuertemente imaginativo, creativo o poiético, y puede desembocar en interpretaciones forzadas o arbitrarias, pero no esotéricas.

Hubo dos maneras de limitar la alegoresis. Una vinculada a la autoridad magisterial de la jerarquía eclesiástica: los resultados debían medirse según la regula fidei, la doctrina de los apóstoles, testigos de Cristo. La otra fue de tipo intelectual o teológica y consistió en la llamada interpretación tipológica de, por ejemplo, Justino Mártir quien, por un lado, piensa que en la Escritura no hay nada insignificante pero, por otro, valora la interpretación literal porque ve que la alegoresis pura de un Orígenes de Alejandría (185-254) resulta poco convincente en el diálogo con el judío. «La tipología consiste en comprobar la correspondencia que existe entre personas, acontecimientos, instituciones y objetos de una época anterior y otros determinados de una época posterior», para lo cual es indiferente que la relación sea posi- 
tiva o negativa; la de Moisés con Cristo o la de Adán con Cristo ${ }^{2}$. En otras palabras, se trataría de aplicar la intepretación alegórica pero únicamente cuando la correspondencia esté directa o indirectamente presente en la literalidad de la misma Escritura.

En cierto modo, la noción de tipo remata la noción de alegoresis: por un lado, logra retener el Antiguo Testamento dentro de la tradición cristiana en calidad de Sagrada Escritura - frente a gnósticos y herejes como Marción que pretendían considerarla al margen del cristianismo- pero, por otro, pone con claridad la diferencia entre ambos testamentos: «los contenidos veterotestamentarios no son más que un presagio y un paradigma de las realidades posteriores» ${ }^{3}$.

A la altura del siglo v, con San Agustín (354-430), la exegesis cristiana está ya completamente formada y emancipada. La Edad Media recogió esa hermenéutica y, sin aportar muchas cosas, la escolastizó, especialmente con la doctrina clásica de los cuatro sentidos de la Escritura: el literal-textual, el alegórico (que descubre la doctrina de la Iglesia en la verdad revelada), el tropológico-moral-práctico (sobre la conducta cristiana) y el anagógico (referido a la escatología final, a la otra vida). Es cierto que el sentido favorito de los medievales fue el alegórico y que se dieron exageraciones en su empleo; pero el sentido literal no quedó del todo olvidado aunque, eso sí, la importancia que se le concedió consistía más bien en una especie de comprobación técnica de seguridad o de mínimos: asegurar que todo el dogma estaba contenido el sentido literal. El pensamiento medieval fue, pues, un pensamiento simbólico.

Lo que me importa ahora es subrayar que Calderón heredó íntegra esta hermenéutica intensamente alegórica y tipológica, de origen patrístico, pero pasada y escolastizada por los medievales, y que esa postura es una marca de su identidad católica.

Pongamos en contraste este sistema exegético con la coyuntura cultural, política y eclesial en que escribe Calderón. Lutero, con su énfasis en la sola Scriptura, rechazó toda alegoresis y devolvió la atención al texto y a su interpretación. Por decir en pocas palabras algo sumamente sabido, los reformadores protestantes llevaron a cabo la ruptura cultural del Humanismo renancentista arrumbando el tradicional pen-

${ }^{2}$ Ver Armstrong, 1962, p. 49; cito por Schreiner, 1974, p. 19.

${ }^{3}$ Ver Schreiner, 1974, p. 19. 
samiento simbólico y poniendo las bases de la aplicación a la Escritura de los métodos histórico-críticos, que se desarrollarían en Alemania en el siglo XVIII y que hasta comienzos del pasado siglo Xx han sido un distintivo de la exegesis protestante frente a la exegesis católica, que hasta ese momento se mantuvo, sustancialmente, en la línea tradicional patrística y medieval. Durante el último siglo xx, la Iglesia católica ha dado entrada a una serie de planteamientos científicos elaborados en el mundo protestante - desde el tratamiento estrictamente filológico de los textos sagrados a la Formgeschichte o la historia de la redacciónpero en tiempos de Calderón, obviamente, eso no era así, en absoluto. Es más, la situación era exactamente la contraria: el modo de tratar la materia bíblica funcionaba como una manera más de marcar la identidad religiosa. Esa «incapacidad para la filología» de que se quejaba Nietzsche, ese recrearse en el pensamiento simbólico, cosa tan barroca, podía ser también una estridente autoafirmación frente a los protestantes, dentro de un universo europeo esencialmente cristiano.

El pensamiento racionalista decimonónico - Compte, Lévy-Bruhl, Durkheim - oponía una mentalidad primitiva y simbólica a una mentalidad evolucionada hacia la lógica y la ciencia. Pero no pasó demasiado tiempo hasta que la antropología estructural descubriera que «no es en el plano de la lógica donde el mito se opone a la ciencia; el mito tiene su lógica, que es la nuestra. El mito no se distingue del pensamiento científico más que por el plano de realidad a que aplica su estrategia» ${ }^{4}$. Según Claude Lévi-Strauss ${ }^{5}$ :

Tal vez un día descubramos que en el pensamiento mítico y en el pensamiento científico opera la misma lógica, y que el hombre ha pensado siempre igualmente bien. El progreso - supuesto que el término pudiera entonces aplicarse - no habría tenido como escenario la conciencia sino el mundo, un mundo donde una humanidad, dotada de facultades constantes, se habría encontrado, en el transcurso de su larga historia, en continua lucha con nuevos objetos» (énfasis mío).

Ahora quizá no nos suene extraña una idea fundamental del pensamiento simbólico patrístico, que formuló Clemente de Alejandría:

4 Ver Ricoeur, 1976, p. 39.

5 1958, p. 210. 
las verdades más elevadas solo pueden expresarse mediante símbolos porque el verdadero conocimiento está más allá del sentido literal. Una idea que los románticos reconocerían como suya, lo mismo que el movimiento simbolista a finales del XIX.

Calderón, por tanto, hace uso del material bíblico dentro de un contexto marcado por el pensamiento simbólico. La razón histórica lleva a afirmar que Calderón depende de los Padres porque, en efecto, es lo que ocurrió. Pero hay, además, una común circunstancia de combate doctrinal o lucha contra la herejía, que acerca a Calderón y la patrística. La primitiva teología cristiana, consciente de que Dios se reveló preliminarmente en la Torá y después en la persona de Cristo, leyó el Antiguo Testamento en función del Nuevo - que poco a poco iba discriminando su propio canon- y ayudó a acuñar fórmulas de fe cada vez más precisas, en función, justamente, de la necesidad de aclarar aspectos de la doctrina de la Iglesia. En aquellos siglos, la Escritura se interpreta como palabra de Dios en el seno de una comunidad dinámica en que los encargados de transmitir la doctrina (los obispos, el magisterio eclesiástico) enseñan al pueblo con autoridad y reciben o rechazan las elaboraciones de los teólogos — muchas veces teólogo y obispo coincide en la misma persona. La catequesis, pues, es un aspecto esencial en una cristiandad que, por un lado, va absorbiendo al mundo pagano y, por otro, distinguiendo entre ortodoxia y herejía.

En el momento en que Calderón escribe sus autos sacramentales, la distinción entre ortodoxia y heterodoxia es de nuevo sumamente relevante. Pero la relación entre dogmática y Escritura ya no es tan dinámica. Porque, en cierto modo, ya todo ha sido interpretado, en especial, después del Concilio de Trento (1545-1562-1563), que sería el último en tres siglos — más bien cuatro, ya que el Vaticano I (18691870) quedó interrumpido durante casi otros cien años hasta el Concilio Vaticano II (1962-1965).

En la teología católica áurea, la doctrina de la Iglesia, dividida en tratados y subdividida en tesis, se prueba primero mediante la Escritura y luego mediante la Tradición, fundamentalmente los Padres y los concilios. En la práctica, en la catequesis particularmente, la Escritura pasa a ser un apoyo para la exposición y justificación del dogma, que es lo prioritario. Se cuenta de un teólogo protestante, Karl Barth, que decía a un amigo católico: «sus teólogos han sustituido la Biblia por el 
Denzinger», el repertorio de las definiciones dogmáticas a lo largo de la historia de los concilios 6 .

Los malos lectores - diría quizá Nietzsche- descubren lo que ya sabían de antemano. En efecto, en este contexto la función primordial de la Biblia como palabra de Dios queda subordinada a la doctrina, a la dogmática, a «lo que se sabe de antemano». Pero también sirve para destacar que la Biblia, tanto entre los judíos como entre los cristianos primitivos y después, no se interpreta de forma individual sino en el seno de una comunidad que engendra una tradición y una especie de circularidad, mayor o menor, más o menos hermenéutica, entre Escritura y Magisterio.

Una relación más bien estática y poco hermenéutica entre Escritura y Magisterio eclesiástico es una marca de la Iglesia católica post-tridentina, volcada hacia la exposición del dogma. Una consecuencia de esa situación es la expansión misional jesuítica en las Indias orientales y occidentales. Otra el esplendor barroco del culto, el arte y la arquitectura. Otra es el esplendor, catequético y alegórico, de los autos sacramentales calderonianos.

Parece inevitable en este momento acudir a las archicitadas palabras del Labrador en la loa del auto La segunda esposa en que se define el género sacramental como «sermones / puestos en verso, en idea / representable, cuestiones / de la Sacra Teología»; y a la no menos frecuentada explicación del concepto de alegoría que hace Pan en el auto que Calderón le dedica, El verdadero Dios Pan:

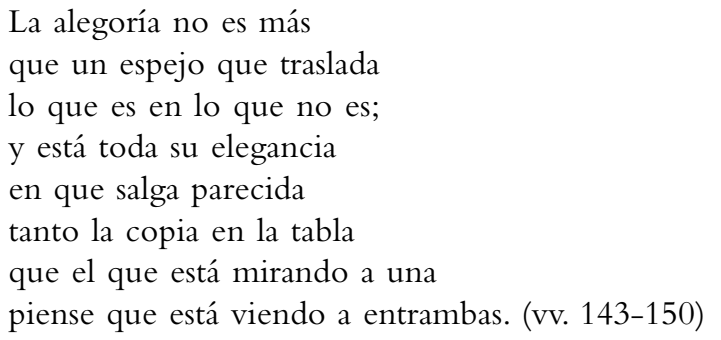

Si aceptamos que los autos son fundamentalmente eso, un sermón, una catequesis - es decir, una reduplicación de la función magisterial

${ }^{6}$ Ver Bouillard, 1976, p. 215. 
de la Iglesia docente hacia la Iglesia discente, distinción muy operante entonces-, a nadie extrañará que el modo de tratar Calderón la Escritura coincida con el modo en que la Iglesia tridentina trata la Escritura.

Es un modo que ha quedado bosquejado más arriba y que desemboca de manera natural en lo que desde hace decenios la teoría literaria ha bautizado como intertextualidad — aunque, naturalmente, el fenómeno había sido percibido y descrito, con bastante precisión, por cierto, bastante antes del estructuralismo y la post-modernidad.

Por ejemplo, Ralph Waldo Emerson (1803-1882) maneja ya la metáfora fundamental de la cita interminable y el texto (el tejido) omnipresente, cuando escribe en «Plato, or the Philosopher» ${ }^{7}$ :

Every book is a quotation; and every house is a quotation out of all forests, and mines, and stone quarries» ['todo libro es una cita; y toda casa es una cita, sacada de los bosques, de las minas y de las canteras']; lo más sorprendente es quizá la conclusión: «and every man is a quotation from all ancestors» ['todo hombre es una cita de sus antecesores'] (p. 25).

En 1933, Ernest Edward Kellett (1864-1950) nos hace ver que la idea de la cita interminable es ya casi un tópico ${ }^{8}$ :

In one sense all, or practically all our writing is quotation. A thousand years of writing have given us a set of vocabularies, each appropriated to particular uses; and no man can write without employing multitudes of phrases the associations of which have been fixed long since and cannot be deliberately altered" ['en cierto sentido, todo o prácticamente todo lo que escribimos es cita. Mil años de escritura nos han dado un conjunto de vocabularios, cada uno de ellos ajustado a usos concretos: y nadie puede escribir sin emplear multitud de frases hechas cuyas asociaciones se han fijado hace mucho y no pueden alterarse deliberadamente'].

No es mucho lo que se sabe de Ernest Edward Kellett ${ }^{9}$ (18641950), jefe del departamento de literatura inglesa en una public school

${ }^{7}$ Ver pp. 24 y 25.

${ }^{8}$ Ver p. 14.

${ }^{9}$ Desde su salida de Leys en 1924, Kellett se dedicó por completo a la crítica literaria, la poesía y el ensayo, que ya había cultivado en sus tiempos de schoolmaster con Monasticism: its ideals and history, and the Confessions of St Augustine: two lectures by 
inglesa, Leys School (Cambridge), el mismo internado privado, de fundación metodista, de donde salió la novela semiautobiográfica Goodbye Mr. Chips cuyo autor, James Hilton, estuvo en Leys entre 1915-1918;

Adolf Harnack (trad. E. E. Kellett y F. H. Marseille, London, Williams and Norgate, 1901) y $A$ book of Cambridge verse (Cambridge, University Press, 1911). El año anterior a su marcha de la escuela había publicado una colección de ensayos Suggestions: literary essays (Cambridge [Eng.], The University Press, 1923), centrados sobre todo en diversos aspectos, bastante originales, de Shakespeare, pero también en cuestiones como «The plastic stress», "Chaucer as a critic of Dante», «John Dryden», «Macaulay's Lay figures» o "The literary detective». Sus intereses por las cuestiones del mito y leyenda aparecen poco después, en The Story of Myths (London, K. Paul, Trench, Trubner \& co., 1927), The Northern saga (London, Leonard \& Virginia Woolf, 1929; atención a los editores), colección y traducción de extractos de sagas islandesas, y The conflict: a saga of the seventh century (London, Constable, 1930), novela histórica sobre el siglo VII. Uno de sus ensayos más apreciados es The whirligig of taste (London, Leonard \& Virginia Woolf, 1929), sobre las revoluciones del gusto literario y de la crítica a través de los siglos. Su propuesta parece consistir, según el necrólogo del Times, «en un relativismo crítico, más bien vago, frente a cualquier noción de ideal o absoluto en literatura». El libro se amplió en 1931 como Fashion in literature, a study of changing taste (London, G. Routledge \& Sons, 1931) y no sé si entiendo bien al necrólogo pero parece que censura a Kellett a cuenta de Fashion: «lo que antes era inadecuado en el debate estético es ahora bastante más notable». Siguió Literary quotation and allusion (Cambridge [Eng.], W. Heffer \& sons, 1933. Reed.: Port Washington, Kennikat Press, 1969), el libro aquí citado, origen de esta nota, y al que ya no atiende el necrólogo. Kellett fue autor de bastantes otros libros, que dan como resultado final una producción considerable que quizá merecería atención desde la historiografía literaria. Parece claro que Kellett responde a la influencia, inmensa entonces, de otro hombre, también radicado en Cambridge, fellow de clásicas en Trinity College, al parecer, desde los 18 años hasta su muerte: James Frazer (1854-1941), el pionero de la antropología comparada y pre-estructural, autor de The Golden Bough (1890; 1906-1915; 1922). La rama dorada es un libro científicamente inservible hoy día - Frazer no viajó, nunca hizo trabajo de campo, se basaba en las encuestas que enviaba a los misioneros- pero que marcó a toda una generación, la de Kellett, y tuvo gran influencia, sobre todo literaria, sobre Wittgenstein, Freud, T. S. Eliot, Robert Graves, D. H. Lawrence o C. S. Lewis; y, de una u otra forma, seguramente también de las sagas de $E l$ señor de los anillos (1954-1955). El punto central de Frazer fue el estudio de los mitos de la antigüedad y su evolución, que vinculó a la magia y, de forma más bien mecánica, a las religiones. En esta línea parecen ir los temas de interés - la antigüedad, el fenómeno religioso, mitos y sagas, la estética literaria- y el planteamiento comparado y marcadamente diacrónico de Kellett, el cual da todo el aspecto de un típico intelectual post-victoriano, recóndito, autodidacta e independiente, muy superado hoy día pero donde quizá no falten intuiciones de peso como la de que «in one sense all, or practically all our writing is quotation». 
aunque no es a Kellett a quien retrata Mr. Chips sino a otro school master, W. H. Balgarnie, encargado del Leys Fortnightly, que es donde Hilton publicó sus primeros cuentos. La necrológica del Times (24 octubre 1950) sobre Kellett habla de su «admiración por los valores intelectuales de la época victoriana», su condición de hijo de clérigo, su educación en un ambiente de piedad Evangélica y su paso por Wadham College, Oxford (probablemente, entre 1904 y 1908) ${ }^{10}$.

Ramón Pérez de Ayala (1880-1962), entre nosotros, y por esos mismos años, imaginó el caso del pintoresco zapatero Belarmino (Belarmino y Apolonio, 1921) que precisamente quiso crear un lenguaje nuevo, liberado de esa red o prisión de las citas inadvertidas. El resultado de semejante alteración deliberada fue la enajenación del personaje y la incomunicación.

También en estos comienzos del siglo xx, pero ya con un contenido teórico definitivo, lo formuló así Mijail Bajtin ${ }^{11}$, el preestructuralista que, en realidad, está en la base de todo el post-estructuralismo:

Indeed, any concrete discourse (utterance) finds the object at which it was directed already as if it were overlain with qualifications, open to dispute, charged with value, already enveloped in an obscuring mist (or, on the contrary, by the «light» of alien words that have been spoken about it). It is entangled, shot through with shared thoughts, points of view, alien value judgements and accents. The word directed towards its object, enters a dialogically agitated and tension-filled environment of alien words,

${ }^{10}$ Otros libros: The appreciation of literature (London, The Epworth Press, 1926); The story of myths, for the use of students in training colleges, and others, London, K. Paul, Trench, Trubner \& co., 1927; Reconsiderations, literary essays (Cambridge [Eng.], The University Press, 1928); A short history of the Jews down to the Roman period (London, Routledge, 1928); A short history of religions (London, Victor Gollancz, 1933; que reedito Penguin en 1962); The saga of the Faroe islanders, trad. M. A. C. Press, introd. E. E. Kellett (London, J. M. Dent \& Sons, 1934); A pageant of history: scenes from 30 centuries (London, M. Joseph, 1936); una autobiografia, As I remember (London,V. Gollancz, 1936); Extracts from Cicero. "De divinatione», ed. E. E. Kellett (Cambridge [Eng.], University Press, 1936); The story of dictatorship from the earliest times till today (London, I. Nicholson \& Watson, 1937); Religion and life in the early Victorian age (London, The Epworth press, E. C. Barton, 1938); Ex libris, confessions of a constant reader (London, G. Allen \& Unwin, 1940).

${ }^{11}$ Ver Bajtin, 1981, p. 276. 
value judgements and accents, weaves in and out of complex interrelationships, merges with some, recoils from others, intersects with yet a third group" ['desde luego, todo discurso concreto (toda expresión) encuentra el objeto al que iba dirigido como ya recubierto con calificativos, abierto a disputa, cargado con valores, envuelto ya en una niebla que lo oscurece o, al contrario, por la luz de palabras ajenas que se han hablado sobre él. Está enredado, atravesado por pensamientos compartidos, puntos de vista, juicios de valor ajenos, acentos. La palabra dirigida hacia su objeto entra en un espacio de palabras ajenas, dialógicamente agitado y lleno de tensión, juicios de valor, acentos; teje por un lado u otro complejas interrelaciones, y converge con algunas, se aparta de otras, se cruza con unas terceras'].

Todorov y otros desarrollaron ese dialogismo de Bajtin, que consiste sustancialmente en descubrir la presencia de "alien words», palabras ajeanas, en un discurso. El término intertextualidad fue acuñado, o al menos consagrado, por Julia Kristeva al teorizar sobre el texto como red de sistemas de signos que se relaciona con otros sistemas de signos — signos ideológicamente marcados - en una determinada cultura. En un ensayo de 1969, precisamente sobre Bajtin - traducido al inglés como «Word, Dialogue and Novel»-, afirma Kristeva que «any text is constructed as a mosaic of quotations; any text is the absorption and transformation of another» de tal forma que "the notion of intertextuality replaces that of intersubjectivity, and poetic language is read as at least double» ${ }^{12}$. Al situar Kristeva la estructura literaria que es el texto dentro de una comunidad o conjunto social considerado como conjunto textual la intertextualidad estaba llamada a superar las limitaciones del formalismo y estructuralismo.

No pretendo hacer ahora un uso teóricamente preciso del concepto de intertextualidad aplicado a los autos en su relación con la

12 Kristeva, 1969, p. 66: «Todo texto está construido como un mosaico de citas. Todo texto es la absorción y transformación de otro texto [...] la noción de intertextualidad reemplaza a la de intersubjetividad, y la lengua poética se lee, al menos, como doble». En 1974 Kristeva reformuló esa noción de intertextualidad en un formato más abstracto, ya con ese juego de paréntesis tan corriente en lo sucesivo entre los académicos: «transposition of one (or several) sign-system(s) into another» ['transposición de uno o varios sistemas de signos en otro'] (Revolution in Poetic Language, 1974, pp. 59-60). Probablemente, deseaba impedir que la intertextualidad se trivializara en una mera localización de citas o fuentes. 
Biblia, pero sí me gustaría sugerir rápidamente una situación de paralelismo. La existencia de una inconsciente e inevitable red de textos desemboca en la existencia de una comunidad de interpretación, ya que es ingenuo pensar que pueda existir un intérprete radicalmente individual, como el Belarmino de Pérez de Ayala. Me limito a señalar que esa noción de "comunidad de interpretación» o "comunidad interpretante» es sumamente familiar a exegesis bíblica cristiana primitiva —no sé si a la judía - y se mantiene incluso, aunque de forma más estática, en la exegesis católica posterior a Trento. La Reforma protestante, en cambio, con su combinación de libre examen y sola Scriptura, debilitó seriamente ese sentido de comunidad, de Iglesia visible, en la interpretación de la Escritura, tanto en el sentido sincrónico —rompió con Roma- como en el diacrónico: rompió con la Tradición.

Los evangelios no son historias o biografias más o menos completas de Jesús. Son documentos que proceden de la catequesis apostólica en las primitivas comunidades cristianas, las cuales extraían de la vida de Cristo una enseñanza de fe. Son la puesta por escrito de un material oral y colectivo, que se servía de todas las formas de relato habituales en aquellas culturas. La apariencia y estructura "parcheada» y como «de aluvión» de los cuatro evangelios denuncia ese origen, que ha permanecido tras el proceso de redacción y canonización, y que fue puesto de relieve por el método histórico crítico, en particular, la Formgeschichte, la historia de las formas.

Todo el juego intertextual del auto sacramental, después de todo, es una manera de tejer materiales pertenecientes a la comunidad de los creyentes. Una particular «historia de las formas» que implica un primer trasvase desde la tradición teológica hacia los autos. Y también otra segunda, aunque menor: de unos autos a otros autos.

Además de mediante la enseñanza, la fe se transmitía mediante la celebración; es decir, mediante la liturgia. Si la catequesis primitiva contenida en los evangelios y la catequesis del auto participan de un proceso de composición semejante (comunitario, intertextual), se me ocurre que podemos plantearnos hasta qué punto el auto participa también de la dimensión litúrgica. Estoy pensando en el día del Corpus y en el proceso íntegro de la procesión que enmarcaba la representación del auto a cielo abierto en el espacio público. Conocemos bien su dimensión de fiesta barroca pero quizá no conocemos su posible dimensión de fiesta litúrgica. Si los sermones ordinarios tenían lugar 
normalmente en el marco de la misa dominical, ¿por qué el marco de estos «sermones representables» no podía ser también litúrgico? Partiendo de un paralelo con la predicación, Tietz ${ }^{13}$ localizó el «espectador implícito" de los autos no en el pueblo, sino en el público ilustrado, un público equiparable al auditorio de un sermón cortesano. Existía, pues, un auditorio plural para los autos ${ }^{14}$. El pueblo no entendía el texto pero sí lo paraverbal visual y auditivo, que es bastante. Ciertamente, como afirma Tietz, la no comprensión del texto no impide su aceptación mediante los factores que sí se captan. A comentarios tan pertinentes, lo que yo añadiría es que el pueblo en el auto se parece mucho al pueblo en la misa dominical; y no tanto en el sermón, del que sí captaría algo - los manuales de predicación recomendaban la máxima sencillez-, sino en el resto de la ceremonia; es decir, en la liturgia propiamente, cuyo latín el pueblo no comprendería en absoluto pero a la que de una manera u otra sí se adhería, como parte del culto religioso, aunque su presencia en el templo no implicara atención a esas accciones. El pueblo comulgaría con el misterio - las divinas palabras de Valle-Inclán- mediante una fe elemental, no mediante la razón. Quizá el texto latino de la misa es el mejor equivalente del texto del auto, dentro de la cosmovisión del hombre del barroco. Lo cual podría acentuar el paralelo que aquí sugiero entre auto y liturgia «estricta»; es decir, paralelo no con la predicación sino con la acción propiamente litúrgica y la actitud del asistente al culto.

Los autos sacramentales han sido estudiados desde el punto de vista textual, literario y teatral. También desde el punto de vista teológico. Que yo sepa, la perspectiva litúrgica no ha sido explorada a fondo, y quizá fuera rentable hacerlo. Acabo de destacar que la Escritura, el Nuevo Testamento, no son biografias de Cristo, no remiten directamente a él, sino a la catequesis de la Iglesia primitiva sobre Cristo. Su forma como texto es resultado de esa circunstancia de enunciación: la enseñanza sobre Jesús que quiere transmitir la Iglesia, una comunidad que interpreta el misterio de Cristo y también los textos que reflejan ese misterio.

13 Tietz, 2006, p. 575.

14 Tietz, 2006, p. 580. 
En consecuencia, la historicidad de los evangelios no significa que ocurrieran de esa manera absolutamente todos los detalles allí narrados. El relato de Emaús, por ejemplo, responde a un anécdota real que, en un momento posterior, se «adorna» o emplea para enseñar la fe de la Iglesia en la celebración eucarística. Concretamente, el relato de la aparición de Jesús resucitado a los caminantes pudo surgir para iluminar el sentido y la estructura de la misa: los primeros cristianos seguían yendo en sábado a la sinagoga a escuchar la palabra de Dios y el domingo celebraban la eucaristía en casas particulares. Al ser expulsados de las sinagogas se reunieron en casas para, primero, leer la Escritura y, después, celebrar la eucaristía: es decir, la misa, tal como la conocemos hoy. Lo cual indica que el empleo del relato de Emaús con ese fin sería posterior a esa expulsión de los cristianos de las sinagogas. La comunidad interpretante de la Iglesia, sobre el hecho real de Jesús resucitado, hizo un relato catequético que vinculaba directamente la celebración eucarística dominical con Jesús resucitado. Para mi objetivo y dicho de otra manera: la celebración eucarística, la misa, no remite directamente a Cristo; tampoco es la Última Cena. Remite a la Iglesia de los apóstoles, a los primeros cristianos. Es el resultado histórico de lo que empezó a hacer la Iglesia primitiva, una comunidad que interpreta a Jesús y también lo celebra. Después de todo, los autos sacramentales se componen también, básicamente, de explicación de textos y celebración eucarística, al igual que la misa.

Los autos calderonianos son una construcción lingüística y teatral de sorprendente unidad y perfección. Su mundo alegórico proyecta una multitud de textos y motivos hacia un mismo tema y significado, sea cual sea el asunto que Calderón decida tratar en cada uno de ellos. Gran parte del mérito artístico le corresponde al gran autor dramático, un poeta del todo excepcional. Pero no debemos subestimar la unidad y coherencia intrínsecas de la tradición sobre la que operaba Calderón: la teología y la liturgia de una comunidad eclesial que se había mantenido fundamentalmente unida durante un milenio y medio. En suma, creo que quizá podemos extender nuestra comprensión de los autos si, además de considerarlos como obra teatral peculiar y como fiesta barroca, los situamos en el contexto de una comunidad que no solo interpreta a Cristo en tanto Escritura y en tanto persona, sino que además lo celebra como liturgia. 
A continuación, voy a fijarme en el uso de la Biblia en un auto sacramental de Calderón titulado Triunfar muriendo ${ }^{15}$. En un trabajo que consideraba como "guión embrionario»" ${ }^{16}$ Ignacio Arellano ha sugerido posibles categorizaciones del modo en que Calderón emplea el inmenso corpus intertextual de la materia bíblica. En primer lugar, habría que tener en cuenta desde la extensión de los motivos, a su integración en la estructura dramática, los personajes emisores, los modos de elocución —narrativa, dialogada, lírica—, la métrica, la música, los símbolos visuales escénicos, las técnicas del resumen o la amplificación (pp. 20-21). También introduce Arellano los conceptos de microtexto, macrotexto parcial y macrotexto argumental.

Si todos los autos sacramentales son intrínsecamente catequéticos, Triunfar muriendo lo es de una manera particular. Yo diría que carece de macrotexto argumental; es decir, que no posee un texto o intertexto que proporcione el esquema argumental completo ${ }^{17}$ como ocurre típicamente con los autos basados en episodios del Antiguo o Nuevo Testamento (La torre de Babilonia, La serpiente de metal, o La semilla y la cizaña; son 23 en total según la clasificación de Valbuena Prat). Lo que encontramos en Triunfar muriendo es, más bien, un encadenamiento de macrotextos parciales («aquellos episodios bíblicos que estructuran la composición y el sentido de fragmentos de cierta extensión dentro de un auto determinado, sin llegar a constituir el armazón fundamental» ${ }^{18}$, que exponen la catequesis básica sobre el ser humano, la Historia salutis en sus dos pasos fundamentales: la Encarnación de Dios en Cristo, Dios-Hombre, y la Redención del hombre del pecado.

Hay también una segunda línea de acción, que esquematizo así: la Encarnación supone la unión de la naturaleza divina y la naturaleza humana en la persona de Cristo. Tal unión semeja unas bodas; pero también es símbolo de la unión de Cristo-esposo con su Iglesia-esposa. A continuación, desde este plano de la teología, Calderón salta

15 Sólo hablaré aquí de Triunfar muriendo, texto refundido por el propio Calderón en 1671 sobre un primitivo auto suyo, basado en las segundas nupcias de Felipe IV, La segunda esposa, de 1648. Para más detalles, ver mi edición crítica de las dos versiones.

16 Arellano, 1999, p. 17.

17 Arellano, 1999, p. 45.

18 Arellano, 1999, p. 35. 
al de la historia al identificar a Cristo con Felipe IV y a la esposa con Mariana de Austria, su segunda esposa desde 1648, tras un largo proceso matrimonial que duró casi tres años (1647-1649), y que constituye el motivo histórico del que partió Calderón para su construcción alegórica.

La estructura. Distingo once secuencias escénicas que podrían distribuirse de la siguiente manera:

i. Introducción y exposición doctrinal: secuencias 1 (vv. 1-201) y 2 (vv. 202-475).

ii. Comienza la acción en dos líneas: secuencias 3, 4, 5, 6 .

iii. Reunión de las dos líneas: secuencia 7.

iv. Clímax: secuencias 8 y 9 .

v. Celebración: secuencias 10, 11.

La Introducción está marcada por una fuerte antitesis entre las dos secuencias de que consta y por la presencia de varias paráfrasis amplificatorias de textos bíblicos. La primera secuencias - serie unitaria de escenas, o de solo una- la protagonizan los personajes positivos: el Rey, los seis Sacramentos ${ }^{19}$, el personaje ancilar del Placer, y la música. Música y Placer exponen el tema central del auto. La Música arranca glosando el título-tema del auto, sobre un intertexto litúrgico, el prefacio de la misa del tiempo pascual: «Pascha nostrum immolatus est Christus. Ipse enim verus est Agnus, qui abstulit peccata mundi. Qui mortem nostram moriendo destruxit et vitam resurgendo reparabit».

Venid, mortales, venid si queréis no serlo y eternos vivir, que aquí está la Vida puesto que está aquí quien, muriendo, a la muerte ha de destruir. (vv. 1-4)

El Placer verbaliza la escena a que asistiremos: «hoy en metáfora un Rey / hace de Gracia una ley / con todos sus sacramentos» (vv. 12-14).

19 Penitencia integra Penitencia y Extremaunción. El número seis resulta así simétrico y más manejable escénicamente que el impar siete. 
El Rey, rodeado de los Sacramentos, inicia una paráfrasis, fundamental para este auto, del texto de Apocalipsis, 21, 2-12, sobre «la Ciudad Santa de Jerusalén, que bajaba del cielo, de junto a Dios», que la Iglesia ha interpretado tradicionalmente como referida a sí misma.

Ya que esa altiva, esa bella

Jerusalén militante

— sombra de la que triunfante

vio en su Apocalipsi aquella

águila [San Juan evangelista] que estrella a estrella...

(vv. 18-22)

El Rey está señalando deícticamente a uno de los cuatro carros que se emplearon para la escenificación del auto: el del Alcázar, que significará «a dos luces», como exige el mecanismo alegórico, tanto la Iglesia como el lugar de residencia de Felipe IV o su joven esposa, según convenga.

Otro microtexto parcial-estructurante en esta primera secuencia es de tipo catequético, no estrictamente bíblico sino teológico. Se trata de la explicación de los sacramentos cristianos como adaptados a las necesidades de la vida del hombre, desde el nacimiento hasta su muerte. El personaje Hombre recorrerá ante el espectador las etapas descritas, por ejemplo, en el siguiente Manuale Sacramentorum publicado por un obispo de Mallorca en 1601:

De estos siete sacramentos, cinco son necesarios para la salvación: el bautismo, la confirmación, la penitencia, la eucaristía y la extremaunción, aunque no todos con la misma necesidad. Por el bautismo nos armamos como soldados de Cristo, llevamos su mismo nombre y somos separados de los gentiles, por lo cual se le llama de manera muy adecuada el sacramento de los que entran (sacramentum intrantium). Por la confirmación nos hacemos sólidos y fuertes en la fe para que no nos avergoncemos de confesarla con audacia en público, y por eso se llama el sacramento de los que luchan. Por si alguien cayera en la lucha la penitencia da el remedio, por eso se la llama también segunda tabla tras el naufragio; con la eucaristía nos reponemos y reanimamos para no desfallecer en la lucha. Finalmente la extremaunción limpia la huella de los pecados de la vida de los que se van y confiere también la salud corporal (In genere sacramentis). 
El Matrimonio (vv. 119-177) hace una glosa de un lugar teológico común según el cual Dios hizo una primera alianza con el pueblo judío, que caducó cuando este se negó a reconocer a Cristo como el Mesías. La nueva Alianza abarca a todos los pueblos y por eso se identifica con la Iglesia católica, es decir, universal:

... ya que la hermosa

Sinagoga, que dichosa

tu primera esposa fue, yace, será justo que

elijas segunda Esposa. (vv. 133-137)

A continuación, una serie de microtextos llevan del plano alegórico al plano histórico que motivó la escritura de la primera versión del auto en 1648:

El tiempo que reinó fiel juraste verla en aumento y pues como "Juramento de Dios» se llamó Isabel... celebres segundas bodas, tú sabes, señor, con quién; pues sabes que desde el día que se lloró su desgracia, Ana, en quien se dice Gracia, previno a tu monarquía, con el nombre de María [...] pues exaltada y graciosa es por todo María y $A n a^{20}$. (vv. 138-167)

Finalmente, Matrimonio es enviado por el Rey a buscar a la Esposa $^{21}$, con lo que se inicia propiamente la acción del auto hasta la apoteosis final.

${ }^{20}$ Isabel: nombre de la prima de la Virgen María y de Isabel de Borbón, primera esposa de Felipe IV. María Ana: hermana de Felipe IV, primera esposa del emperador Fernado III, y madre de Mariana de Austria, que tenía 13 años cuando se decidió su boda con su tío Felipe IV. Ana: madre de María Virgen, madre de Cristo.

${ }^{21}$ Las fechas de 1647 son: 12 enero, primer anuncio del compromiso matrimonial. 26 enero, firma del contrato matrimonial en Madrid. 13 junio, firma del con- 
Tras la salida de escena de todos los personajes positivos y la repetición musical del estribillo, que funciona hábilmente como cierre y enlace, se inicia la secuencia segunda (vv. 202-475) de la Introducción. La protagonizan los dos personajes negativos: la Muerte y el PecadoDemonio. Esta secuencia segunda es una escenificación, un intertexto escénico de Romanos, 5, 12: «Por tanto, así como por medio de un solo hombre entró el pecado en el mundo, y a través del pecado la muerte, y de esta forma la muerte llegó a todos los hombres, porque todos pecaron». La Muerte, confusa ante la visión del carro del PalacioAlcázar-Jerusalén-Iglesia y el sonido del cantable «está aquí / quien, muriendo, a la Muerte ha de destruir», llama al Pecado y expone un nuevo microtexto, parcial pero estructurante, que parafrasea la caída del hombre en el pecado. Es decir, Génesis, 3-4:

\author{
Ya sabes que mi principio \\ fue en el hermoso jardín \\ de la original justicia, \\ adonde engendrada fui \\ de la voz de la serpiente... (vv. 264-268)
}

A este intertexto se agregan otros de Apocalipsis (12, 7-9), Ezequiel (18) y 2 Pedro $(2,4)$ sobre la rebelión de Lucifer contra Dios y la batalla de los ángeles malos contra los ángeles buenos encabezados por San Miguel:

Muerte

\author{
Pero mal hago, mal hago \\ en alegar desde aquí \\ mi origen, puesto que \\ es más antiguo que referí $[\ldots]$ \\ Pues antes que el todo y nada \\ tú [Pecado-demonio] me concebiste en ti
}

trato matrimonial en Viena. 11 agosto, Felipe IV escribe formalmente al Ayuntamiento de Madrid anunciando su boda. 1648: 8 noviembre, matrimonio por poderes en Viena. Mariana inicia viaje a Madrid, que dura un año, pasando por Trento y Génova. Travesía del Mediterráneo. Diciembre 1648: Mariana cumple 14 años. 1649: septiembre, llegada al puerto de Denia. Salida hacia Madrid, pasando por Navalcarnero y El Escorial. Noviembre, llegada a Madrid e instalación en el Palacio del Buen Retiro. 15 noviembre, solemne traslado de Mariana desde el Buen Retiro al Alcázar. Gran fiesta ciudadana. 


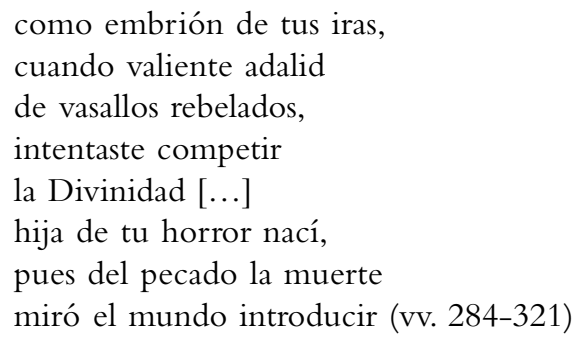

Tras glosar la primera muerte de la humanidad, la de Abel a manos de Caín, Calderón alude a un microintertexto de origen litúrgico, el himno "Dies irae», procedente de la Misa de Difuntos; este le conduce a una alusión histórica (la muerte en 1646 de la emperatriz María, madre de la nueva esposa), que remata en dos nuevos intertextos sobre la muerte y el pecado: «Mira que en culpa nací, / pecador me concibió mi madre» (Salmo, 51, 7) y «Statutum est hominibus semel mori» (Hebreos, 9, 27).

Terminada esta paráfrasis, la Muerte regresa al motivo central de esta secuencia: el texto del cantable, vinculado escénicamente al carro del palacio, puesto que el sonido sale de allí. La descripción de esta «fábrica bella» (v. 382) o "máquina» (v. 416) se apoya en los pasajes bíblicos relativos al Templo de Salomón (1 Reyes, 5-7; 1 Crónicas, 29; 2 Crónicas, 2, 3-4), que es, una vez más, figura de la Iglesia cristiana y que tiene una importancia trascendental en el paso del judaísmo al cristianismo. En efecto, la idea fundamental de que el Templo había caducado y que Cristo era el Nuevo y definitivo Templo para toda la humanidad partía de otros textos clave. Concretamente, el salmo 118, 22: «La piedra que desecharon los constructores ésta ha llegado a ser la piedra angular»; a continuación el texto en que Mateo —el evangelista que se dirige a judeocristianos, sumamente familiarizados con el Antiguo Testamento- vincula deliberadamente el Bautismo de Cristo en el Jordán con la escala de Jacob, citada en Triunfar muriendo. Dice Mateo: «Inmediatamente después de ser bautizado, Jesús salió del agua; y entonces se le abrieron los cielos, y vio al Espíritu de Dios que descendía en forma de paloma y venía sobre él» $(3,16)$. Juan, por su parte, es categórico: «-Destruid este Templo y en tres días lo levantaré». Los judíos no entienden: «-¿En cuarenta y seis años ha sido construido este Templo, y tú lo vas a levantar en tres días? Pero él se refería al Templo de su cuerpo. Cuando resucitó de entre los muer- 
tos, recordaron sus discípulos que él había dicho esto, y creyeron en la Escritura y en las palabras que había pronunciado Jesús» (2, 19-22). El carro del palacio representa visualmente toda esta interpretación.

Destaco la alusión a los sacramentos (vv. 407-415), mediante su respectiva materia:

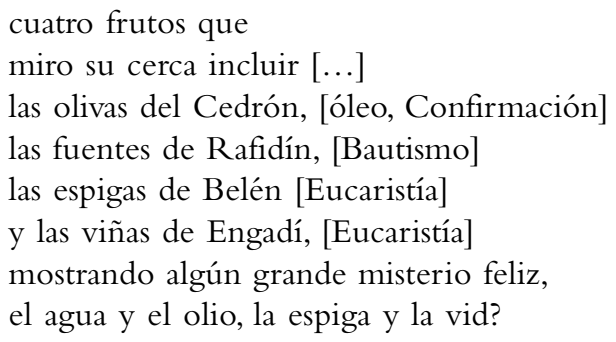

Tras una nueva alusión de Muerte a la expulsión del hombre del Paraíso (Génesis, 3, 23-24), entra Pecado (en realidad el Demonio), cuya incapacidad para los misterios sobrenaturales - Santo Tomás en Suma Teológica, I, 58, 5- le remite a la citada figura de la Iglesia, la escala de Jacob (Génesis, 28, 10-22):

\author{
[...] aquella \\ grande escala que ceñía \\ cielo y tierra, en que se vía \\ subir y bajar por ella \\ tropa de alados querubes \\ bien como aquí resplandores \\ del tapete de las flores \\ al volante de las nubes (vv. 466-473)
}

La salida de Placer cierra este primer bloque de Introducción e inicia propiamente la acción del auto, con sus dos brazos: la historia de la salvación del hombre y la historia de las bodas del Rey-CristoFelipe IV con la Naturaleza Humana-Iglesia-Mariana de Austria.

A partir de ahora, me limito a un análisis solo macroestructural.

Secuencia 3: se centra en el segundo de los brazos de acción mediante la parábola de los invitados a las bodas sobre el texto de Mateo, 22, 1-14 y los de San Gregorio Magno (hom. 38, In evangelium a Mt 22), San Juan $(6,22-59)$ y San Pablo (1 Corintios, 11, 23-32). Entra en juego escénico un segundo carro (el del trono) en que la Esposa recibe 
a Matrimonio, que la desposa por poderes, dando lugar a sendas paráfrasis de la oración "Ave María» y de los himnos "Salve, Regina» y «Magníficat». Esta línea de acción ligada a las bodas y a la Esposa queda interrumpida para dar paso a la otra línea centrada en el Hombre.

Secuencia 4. Del carro del peñasco (carro 3) sale, por vez primera, el Hombre, con seis velas encendidas. Su salida del peñasco (primer Adán) y su indumentaria expresan su situación arquetípica: nace de la tierra y es peregrino. Acosado desde el principio por el Pecado (original) que le imprime su marca con un hierro, el Hombre es capaz de llegar a Dios gracias a su razón natural, pero cae en manos de la Muerte, que le apaga cinco de sus seis velas: el hombre está sometido al dolor, una muerte en vida.

Secuencia 5. Al pedir auxilio al carro del Palacio (carro 1), salen los seis sacramentos: Bautismo le quita la marca del pecado original y Confirmación le hace crecer a perfecta edad. Penitencia le libra de la cadena de los pecados posteriores al Bautismo. Comunión le alimenta en su debilidad y Orden no solo explica la doctrina del Pan deVida (función magisterial del Orden) sino que hace presente al Rey (función sacramental del Orden sacerdotal).

Secuencia 6. Reunidos todos los integrantes de esta línea temática y de acción, surge el Rey y culmina esta Historia salutis, pues representa la Eucaristía (al ser invocado por Orden) y la Encarnación (toma la vela que le entrega el Hombre).

Secuencia 7. Esta escena supone la reunión de esta línea de la Historia Salutis con la de las Bodas, que quedó suspendida en la secuencia 3. El Placer relata su embajada, frustrada por la mala respuesta de judaísmo y gentilismo, los invitados descorteses de la parábola de Mateo. El desplante da paso a alusiones históricas: la guerra contra los enemigos de la monarquía austríaca.

Secuencias 8 y 9. Son las escenas de clímax: bodas y guerras. Para darle mayor realce, Placer introduce, como extraescénica, el episodio que contemplamos a continuación: la lucha a espada de Pecado y Muerte contra Rey-Cristo, y el triunfo de este, apoyado en una cruz. La salida inmediata de los sacramentos (escena 9) expresa la interpretación patrística de que la Iglesia y los sacramentos nacen del costado abierto de Cristo, perpetuando la victoria de Cristo sobre el Pecado y la Muerte. Por eso a estos los llevan cautivos Penitencia y Comunión. 
Secuencia 10. El monólogo de Hombre, paráfrasis de los prodigios deViernes Santo (Mateo, 27, 51-54), desemboca en el triunfo de Cristo en la Resurrección, que se identifica con la revalidación de sus Bodas con la Esposa.

Secuencia 11. Celebración y esplendor escenográfico, iconológico y musical. Entra en función el carro cuarto, el de la Nave, donde aparece la Esposa en la popa, el Matrimonio en la proa y un coro de músicos en los costados. A continuación se abre el carro del trono o carro triunfal (carro 3), con el Rey sentado en él, Muerte y Pecado a sus pies, y los sacramentos como contracoro.

Con todos los personajes en el tablado, y los cuatro carros en acción simultáneamente, la escena se articula en dos polos sobre dos elementos alegóricos predominantes: la Nave del Mercader (de perlas), cruce de Proverbios $(31,14)$ y la parábola de la perla preciosa de Mateo (13, 45-46), y el Carro de Ezequiel (Ezequiel, 1; Eclesiástico-Ben Sirac, 49-8).

Rey-Triunfo y Esposa-Nave emprenden un epitalamio antifonal que termina en una catequesis visual centrada en la Eucaristía, como es preceptivo en el género. Se abre el carro del palacio (carro 1) «y vese en él un león en pie sobre un altar, el cual, abriéndose en dos mitades, tiene dentro un cordero». Seguidamente, «ábrese el carro del peñasco [carro 2] y vese en él un águila imperial que abriéndose en dos mitades tiene dentro una paloma».

En un segundo momento, "Ábrese el cordero y vese dentro un Niño de Pasión con la cruz a cuestas y demás insignias en un canastico».Y también «Ábrese la paloma y vese dentro hostia y cáliz».

Hay, pues, dos series alegóricas:

-Esposo en carro del triunfo: palacio-león-cordero-Niño de Pasión, $\mathrm{y}$

—Esposa en nave: peñasco-águila-paloma-hostia y cáliz.

Ambas visualizan las dos líneas de acción del auto, y las identifican: Christus passus y la Iglesia confluyen finalmente en el misterio de la Eucaristía, el de Corpus Christi. Una vez más, Calderón ha compuesto una estructura sumamente compleja y perfectamente unitaria. 


\section{Bibliografía}

Arellano, I., «Notas sobre la Biblia en los autos de Calderón», en V Simposio Bíblico Español: la Biblia en el arte y en la literatura, ed. V. Balaguer y V. Collado, Valencia, Fundación Bíblica Española, 1999, pp. 17-52.

Armstrong, G. T., Die Genesis in der Alten Kirche, Die drei Kirchenväter, Tübingen, 1962.

Boulllard, H., «Exégesis, hermenéutica y teología. Problemas de método», en Exégesis y hermenéutica, ed. R. Barthes y otros, trad. G.Torrente Ballester, Madrid, Cristiandad, 1976, pp. 213-224.

Bakhtin, M. M., "Discourse in the novel», en The Dialogic Imagination: four essays by M. M. Bakhtin, ed. M. Holquist, trad. C. Emerson y M. Holquist, Austin, University of Texas Press, 1981, pp. 259-422.

Calderón de la Barca, Pedro, El verdadero Dios Pan, ed. F. Antonucci, Kassel, / Pamplona, Reichenberger / Universidad de Navarra, 2005.

- La segunda esposa y triunfar muriendo, ed. de las dos versiones, estudio, bibliografia y notas de V. García Ruiz, Kassel, / Pamplona, Reichenberger / Universidad de Navarra, 1992.

- Obras completas, vol. 3, Autos sacramentales, ed. Á. Valbuena Prat, Madrid, Aguilar, 1952.

Emerson, R. W., «Plato, or the Philosopher», en Representative men: seven lec tures, introduction by B. Wineapple, New York, Modern Library, 2004, pp. 23-52.

Lévi-Strauss, C., Antropología estructural, trad. E.Verón, Buenos Aires, Editorial Universitaria de Buenos Aires, 1968. Original: L'Anthropologie structurale, Paris, Plon, 1958.

Kellet, E. E., Literary Quotation and Allusion, Cambridge, Heder \& Sons, 1933.

Kristeva, J., "Problèmes de la structuration du texte», en La Nouvelle critique, Número especial, Actes du Colloque de Cluny, 16-17 abril, 1968, pp. 5564.

- Revolution in Poetic Language, trad. M. Waller, New York, Columbia University Press, 1984.

- «Word, Dialogue and Novel», en Desire in language: a semiotic approach to literature and art, ed. L. S. Roudiez, trad.T. Gora, A. Jardine, y L. S. Roudiez, Oxford, Blackwell, 1981, pp. 64-91.

Nietzsche, F., El Anticristo: maldición sobre el cristianismo, introd., traducción y notas A. Sánchez Pascual, Madrid, Alianza, 1997.

Ricoeur, P., «Del conflicto a la convergencia de los métodos en exégesis bíblica», en Exégesis y hermenéutica, ed. R. Barthes y otros, trad. G. Torrente Ballester, Madrid, Cristiandad, 1976, pp. 33-50. 
SCHREINER, J., «Breve historia de la exégesis veterotestamentaria: épocas, objetivos, caminos», en Introducción a los métodos de la exégesis bíblica, ed. J. Schreiner, Barcelona, Herder, 1974, pp. 11-31.

Tietz, M., «El "espectador implícito" en los autos sacramentales de Pedro Calderón de la Barca», La dramaturgia calderoniana, ed. I. Arellano y E. Cancelliere, Madrid, Iberoamericana / Frankfurt am Main,Vervuert, 2006, pp. 561-586.

Valbuena Prat, Á., «Los autos sacramentales de Calderón», Revue Hispanique, 61, 1924, pp. 1-302. 
